\title{
GRUPOS DE PESQUISA EM CIÊNCIA DA INFORMAÇÃO DA REGIÃO NORDESTE DO BRASIL: ANÁLISE DA PRODUÇÃO, TEMÁTICAS E DISSEMINAÇÃO DA COMUNICAÇÃ̃O CIENTÍFICA
}

\author{
RESEARCH GROUPS IN INFORMATION SCIENCE IN \\ THE NORTHEAST REGION OF BRAZIL: ANALYSIS OF \\ PRODUCTION, THEMES AND DISSEMINATION OF \\ SCIENTIFIC COMMUNICATION
}

Andreza Pereira Batista ${ }^{a}$

Gabriela Belmont de Farias ${ }^{b}$

\begin{abstract}
RESUMO
Introdução: A produção científica brasileira é fomentada por meio dos estudos desenvolvidos por grupos de pesquisa, especialmente os que estão registrados no Conselho Nacional de Desenvolvimento Científico e Tecnológico (CNPq). Estes grupos são ligados a instituições de ensino e pesquisa, em particular às Universidades Públicas Federais. Em vista disso, o artigo tem como questões de partida: quais as principais temáticas dos grupos de pesquisa em Ciência da Informação da Região Nordeste do Brasil e quais os meios de comunicação mais utilizados pelos líderes dos grupos para a disseminação das produções científicas? Objetivo: apresentar o cenário da produção dos Grupos de Pesquisa nordestinos em Ciência da Informação, cadastrados no Diretório dos Grupos de Pesquisa no Brasil do CNPq, suas principais abordagens temáticas e os veículos de comunicação utilizados. Metodologia: aplica como método o estudo de caso, utilizando como instrumento de coleta de dados o Diretório dos Grupos de Pesquisa e as produções publicadas pelos líderes dos grupos na base de dados Web of Science e para a análise a metodologia Análise de Conteúdo. Resultados: aponta que os Grupos de Pesquisa em Ciência da Informação nordestinos são focados em pesquisas relacionadas às temáticas: gestão, mediação e tecnologia da informação, utilizando como suporte de disseminação de suas pesquisas os artigos em periódicos científicos. Conclusões: os Grupos de Pesquisa nordestinos possuem publicações científicas de qualidade e publicadas em periódicos com Qualis/Capes, demonstrando o comprometimento dos pesquisadores em produzir conhecimentos para a (re)utilização pela comunidade acadêmica, e consequentemente, para a sociedade.
\end{abstract}

Descritores: Ciência da Informação. Comunicação Científica. Gestão da Informação.

a Graduanda do Curso de Biblioteconomia da Universidade Federal do Ceará. Bolsista PIBIC. Email: andrezapereira028@gmail.com

b Doutora em Ciência da Informação pela Universidade Estadual Paulista Júlio de Mesquita Filho (UNESP). Docente do Departamento de Ciências da Informação e do Programa de Ciência da Informação da Universidade Federal do Ceará (UFC). E-mail: gabibfarias@gmail.com 
Grupos de Pesquisa. Produção Científica.

\section{INTRODUÇÃO}

A pesquisa científica é evidenciada por meio de sua produção, onde há a visualização concreta do que é realizado no âmbito da ciência. No Brasil, cerca de $60 \%$ do total da produção científica correspondem a 15 instituições públicas, sendo 12 delas, universidades federais, segundo dados da Clarivate Analytics (2019).

Destarte essa questão, as produções dessas universidades advêm de seus grupos de pesquisa (GPs), laboratórios e de parcerias institucionais, principalmente no contexto dos programas de pós-graduações. Nesse ínterim, os GPs são reconhecidos como pontos convergentes de interações entre pesquisadores de temáticas iguais e/ou similares, trazendo contribuições tanto para aqueles que dela integram, quanto para a ciência no país.

Os GPs em diferentes áreas podem trazer a tona indicativos do contexto atual das investigações científicas, especialmente no que concerne a informações disponibilizadas pelos censos do Diretório Geral de Pesquisa no Brasil (DGP) do Conselho Nacional de Desenvolvimento Científico e Tecnológico (CNPq), que podem ser exploradas sob diferentes óticas. Isto posto, este artigo tem como pergunta de partida: quais as principais temáticas dos GPs em Ciência da Informação $(\mathrm{Cl})$ da Região Nordeste do Brasil e quais os meios de comunicação mais utilizados pelos líderes dos grupos para a disseminação das produções científicas?

Por conseguinte, o objetivo está em apresentar o cenário, as principais abordagens temáticas da produção e os veículos de comunicação utilizados pelos líderes dos GPs em CI na Região Nordeste cadastrados no DGP do CNPq, por meio da análise das produções publicadas pelos líderes dos grupos na base de dados Web of Science (WOS), da Clarivate Analytics. 


\section{DIRETÓRIO DOS GRUPOS DE PESQUISA DO BRASIL DO CNPQ}

As cooperações entre pesquisadores são reconhecidas como constante em um contexto no qual a ciência desenvolve-se a partir de estudos especializados. Assim, passa a ser comum que pesquisadores com áreas de atuação e interesse semelhantes ou iguais contribuírem entre si para a promoção de novos conhecimentos. Nesse cenário, os GPs agem como promotores dessas contribuições entre esses sujeitos atuantes na ciência. Segundo o DGP, vinculado ao CNPq, os GPs definem-se como:

[...] um conjunto de indivíduos organizados hierarquicamente em torno de uma ou, eventualmente, duas lideranças:

- cujo fundamento organizador dessa hierarquia é a experiência, o destaque e a liderança no terreno científico ou tecnológico;

- No qual existe envolvimento profissional e permanente com a atividade de pesquisa;

- cujo trabalho se organiza em torno de linhas comuns de pesquisa que subordinam-se ao grupo (e não ao contrário);

- E que, em algum grau, compartilha instalações e equipamentos. O conceito de grupo admite aquele composto de apenas um pesquisador e seus estudantes. (CNPq, [201-]e, online).

De acordo com essa definição, os líderes configuram-se como aqueles que detém a liderança acadêmica e individual no ambiente de pesquisa, com as funções de coordenação e planejamento das atividades do grupo, podendo ter até dois líderes. O CNPq ([201-]f) aponta que o 1ํ e o 2ํlíder tem o mesmo "peso", todavia, o que os diferencia é que o primeiro é responsável pelo preenchimento das informações no DGP. Isso ocorre para evitar problemas com o acesso simultâneo, além de contradições de dados.

Além disso, a definição apresentada pelo DGP ainda foca nas linhas de pesquisa que subordinam-se ao grupo, onde, segundo o órgão, representam os temas aglutinadores de estudos científicos que fundamentam em tradição investigativa. Delas, originam-se projetos cujos resultados guardam afinidades entre si. Um grupo pode ter mais de uma linha de pesquisa e elas não precisam estar necessariamente relacionadas a todos seus integrantes.

Consequentemente, os GPs são redes de interações que permitem a seus membros a integração e troca constante de informação, obtendo assim condições de produções que contribuem diretamente para o progresso das práticas científicas. 
Nesse contexto, Lopes e Lobo (2016) afirmam que com advento da internet, colaborar cientificamente não é mais um problema geográfico, uma vez que muitas pesquisas podem ser conduzidas sem a necessidade presencial dos pesquisadores, geridas por meio de ferramentas online.

Acerca dessa questão, Deus (1979, p. 20), reflete sobre a ligação da ciência à tecnologia, sendo este um dos aspectos mais delicados na compreensão do papel da ciência nas sociedades modernas. "Em que medida é que a ciência mudou a função da tecnologia?".

Pode-se apontar que seria uma mudança mútua, onde a ciência dá a tecnologia mecanismos de existência e a tecnologia a retorna com, além de todas as facilidades de comunicação e outros, o estreitamento das relações entre pesquisadores de interesses convergentes.

Assim, visando ser um inventário dos GPs científicos e tecnológicos em atividade no Brasil, possuindo uma base corrente ${ }^{1}$ e com informações atualizadas continuamente pelos atores envolvidos, o já citado DGP reúne dados que dizem respeito aos recursos humanos constituintes dos grupos e seus membros (pesquisadores, estudantes e técnicos), às linhas de pesquisa, especialidades, produção científica, tecnológica e artística do grupo de pesquisa (C, T\&A) e parcerias em andamento (CNPq, [201-]h).

Em posse dessas informações, o diretório consegue estabelecer o perfil geral e escrever os limites da atividade científico-tecnológica no Brasil. A figura 1 demonstra os objetivos do DGP.

\section{Figura 1 - Objetivos do DGP do CNPq}

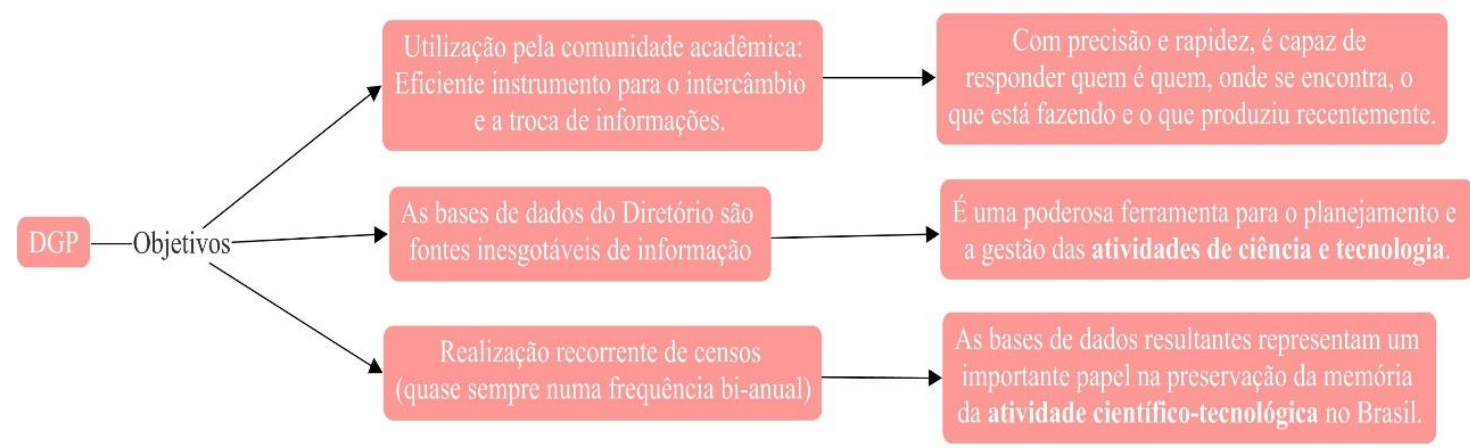

\footnotetext{
${ }^{1}$ A base corrente é composta pelos grupos de pesquisa certificados pelos dirigentes das instituições participantes (universidades, instituições isoladas de ensino, institutos públicos de pesquisa e outras) (CNPq, [20--]b).
} 
Fonte: elaborado pelas autoras (2019) com base em Conselho Nacional de Desenvolvimento Científico e Tecnológico ([201-]i).

Na figura 1 é possível perceber que o foco do diretório é apresentar dados consistentes da atividade científico-tecnológica no cenário brasileiro, apresentando-se como uma fonte inesgotável de estudos e pesquisas, como o presente artigo.

Esses dados são obtidos mediante censos, geralmente bianuais, onde são coletadas, atualmente, informações vinculadas ao Currículo Lattes (CVLattes) cadastrados no CNPq, sendo condição para a integração de um membro no sistema. A base censitária² é composta por GPs certificados, existentes na base corrente, pela produção C, T\&A do quadriênio em avaliação existente na base do currículo (CNPq, [201-]j).

Ainda segundo informações do CNPq ([201-]c), foram realizados 11 censos (1993, 1995, 1997, 2000, 2002, 2004, 2006, 2008, 2010, 2014 e 2016), cujos resultados encontram-se no portal do DGP. O censo atual, de 2016, apresenta resultados referentes a 531 instituições com registro de 37.640 grupos e 199.566 pesquisadores.

O DGP apresenta em sua base censitária as séries históricas e as súmulas estatísticas dos dados obtidos dos censos. Ambos contêm gráficos e tabelas com informações que sintetizam a evolução temporal do perfil dos grupos, com a diferença que as súmulas apresentam pequenos retratos desses dados. Abaixo encontram-se os dados provenientes dos censos mencionados anteriormente, restringindo-se ao mais atual, do ano de 2016.

\section{Gráfico 1 - Evolução Grupos de Pesquisa por Ano}

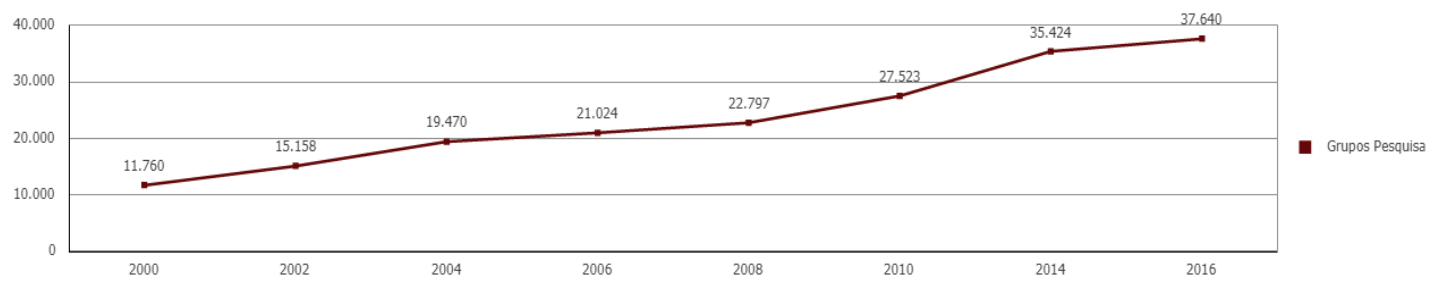

Fonte: Conselho Nacional de Desenvolvimento Científico e Tecnológico (2016a).

\footnotetext{
${ }^{2}$ De acordo com o CNPq ([201-]a), a base censitária é uma "fotografia" da base corrente do DGP, tirada numa frequência quase bienal para realizar um censo da capacidade de pesquisa no país. Agrega a produção C, T\&A do grupo de pesquisa, constituída pela soma das produções.
} 
No gráfico 1, é possível visualizar o crescimento dos grupos de pesquisa ao longo dos anos, desde 2000, ano no qual realizou-se o primeiro censo pelo DGP, onde o mais expressivo refere-se a 2014, ano em que registraram-se 35.424 GPs. No gráfico 2, abaixo, demonstra-se os GPs por grande área no censo de 2016, sendo a Ciências Humanas a que contém o maior quantitativo de GPs, com $21 \%$, seguida por Ciências da Saúde, com 16\%, pelas Ciências Sociais Aplicadas, com 14\%, e pelas Engenharias e Computação, com 13\%.

\section{Gráfico 2 - Grupos de Pesquisa por Grande Área}

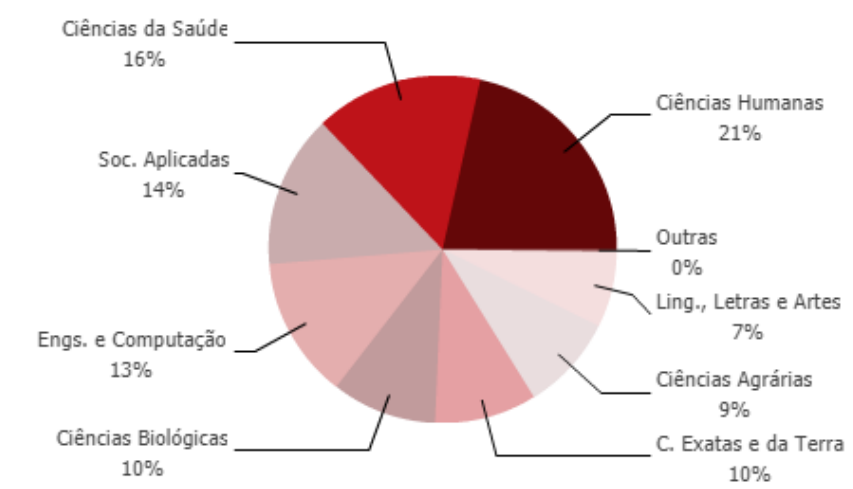

Fonte: Conselho Nacional de Desenvolvimento Científico e Tecnológico (2016a).

Para fins deste artigo, elegeu-se como área de análise a Ciências Sociais Aplicadas. Dentro dessa grande área, encontram-se as áreas Direito, Administração, Comunicação, Economia, Arquitetura e Urbanismo, Serviço Social, Ciência da Informação, Planejamento Urbano e Regional, Turismo e Museologia. Conforme os objetivos estabelecidos, a área em foco é a $\mathrm{Cl}$, que apresenta 259 grupos contabilizados na análise do censo 2016 .

Os GPs estão ligados em sua grande maioria a instituições, dentro de federações do Brasil, estes dados representam cenários regionais ligados a pesquisa no país, que podem ser observados no gráfico 3 .

\section{Gráfico 3 - Grupos de Pesquisa por Região}

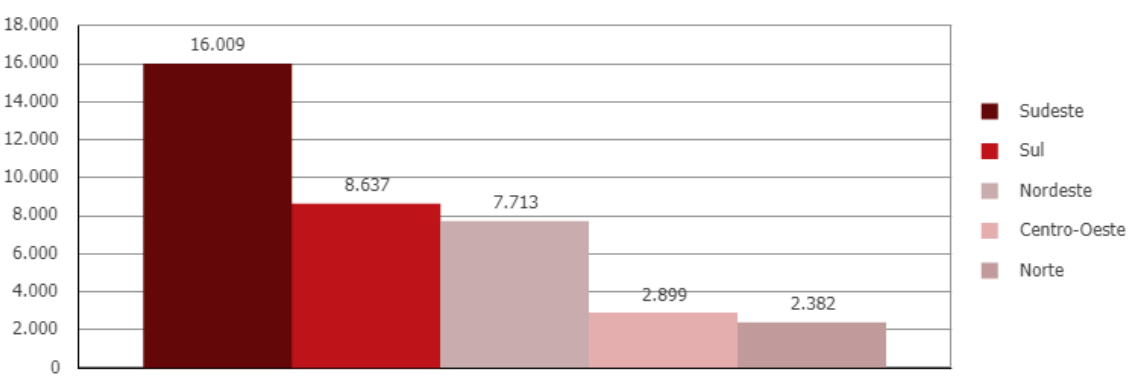

Fonte: Conselho Nacional de Desenvolvimento Científico e Tecnológico (2016a). 
Apesar dos maiores índices encontrarem-se nas regiões Sudeste e Sul, o que se pode compreender pelos investimentos em pesquisas nas regiões, os estados do Nordeste apresentam indicativos de GPs contabilizados pelo CNPq, com 7.713 grupos. Ela corresponde a $20 \%$ da soma total dos grupos no Brasil, estando distribuídos não somente em universidades, mas presente em outras instituições de ensino, como institutos e organizações.

O gráfico 4 traz as especificações dos GPs na citada região, em que é perceptível no gráfico que os estados da região que mais apresentam GPs cadastrados no DGP são Bahia (com 1.821), Pernambuco (com 1.316), Paraíba (com 1.056) e Ceará (com 976).

\section{Gráfico 4 - Grupos de Pesquisa na Região Nordeste do Brasil}

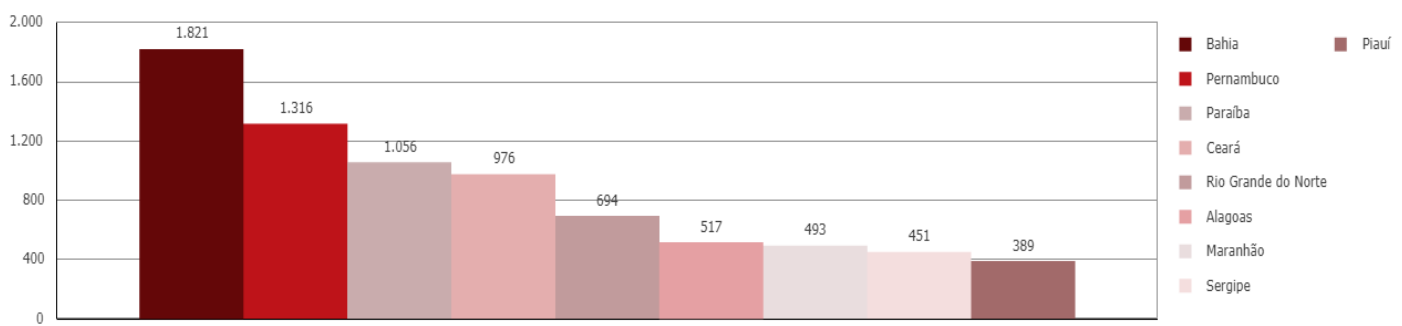

Fonte: Conselho Nacional de Desenvolvimento Científico e Tecnológico (2016a).

Ademais, conforme apresentado, visualizam-se crescimentos significativos de muitas áreas, entretanto, conforme já explicitado, os censos levam em consideração a produção C, T\&A dos GPs. Logo, é necessário debruçar-se nessa questão, onde é perceptível a contribuição desses grupos para a pesquisa no Brasil.

\subsection{Produção Científica nos Grupos de Pesquisa}

A ciência busca responder a questões fundamentadas nos fenômenos observados na sociedade. Essas respostas são obtidas mediantes pesquisas científicas de diversas naturezas e áreas de conhecimento, sendo transmitidas por meio de comunicações formais e informais, denominadas de produções científicas.

Segundo Droescher e Silva (2014, p. 176), "[...] as publicações científicas podem ser consideradas como o principal meio pelo qual os pesquisadores se 
destacam academicamente, ou seja, se tornam visíveis à comunidade acadêmica" e para, além disso, tornam-se notórios para estatísticas, estudos e parcerias, com possibilidade de contribuição social ainda mais consistente.

No contexto dos grupos de pesquisa, essa realidade torna-se ainda mais presente, uma vez que a produção dos membros do GP é levada em consideração para o censo do DGP, já explanado previamente. De acordo com o CNPq ([201-]h), a produção C, T\&A de um grupo é:

[...] a soma das produções existentes nos currículos Lattes dos pesquisadores, estudantes e técnicos integrantes do grupo. A produção de um pesquisador, estudante ou técnico que participa de mais de um grupo é contada uma vez em cada grupo. A produção só é extraída da base de CVLattes e atribuída aos grupos de pesquisa na ocasião dos Censos e o período considerado é, quase sempre, relativo aos quatro últimos anos, incluindo o ano censitário. Na Base Corrente do Diretório, não é informada a produção do grupo, mas apenas a produção de cada participante, individualmente.

Desse modo, o DGP leva em conta as produções separadamente dos integrantes dentro do período em análise, utilizando-se para isso o que está cadastrado no CVLattes de cada um individualmente. No entanto, compreendese que essa metodologia pode não demonstrar o panorama total dessas produções, uma vez que membros de grupos que não atualizam de forma constante as informações presentes no seu currículo podem prejudicar a extração dos dados.

Dessarte, os dados componentes do censo do DGP acerca da produção e produtividade C, T\&A dividem-se por tipos, contendo (CNPq, 2016b):

a) artigos completos de circulação nacional e internacional (ambos em tabelas próprias);

b) trabalhos completos publicados em anais de eventos técnicos e científicos;

c) livros e capítulos de livros;

d) produção técnica (enquadram-se softwares, produtos e processos tecnológicos, com ou sem patente, registro e/ou catálogo); e

e) teses e dissertações defendidas sob orientação de pesquisadores doutores cadastrados nos grupos. 
O CNPq (2016b) ressalta que os dados dizem respeito à produção dos pesquisadores doutores informados em seus CVLattes até o momento da coleta pelo DGP, referentes aos quatro anos anteriores ao Censo.

Ademais, não foram identificadas informações gerais sobre os tipos das produções e suas respectivas porcentagens mais utilizadas em cada área de conhecimento. Essa informação poderia contribuir para o reconhecimento das tipologias comuns às áreas e, talvez, para um possível trabalho de divulgações científicas de seus resultados.

\section{METODOLOGIA}

A pesquisa caracteriza-se como sendo um estudo de caso, no qual permite conhecer melhor as particularidades delineadas pelo universo dos grupos de pesquisa da região nordeste. Sendo assim, sua escolha condiz com o que Prodanov e Freitas (2013, p. 62) afirmam sobre esse estudo, "permitir explorar variáveis causais de determinados fenômenos e descrever situações em que está sendo realizado determinada investigação".

Dito isso, para a análise dos dados coletados a partir do estudo de caso, foi escolhido a Análise de Conteúdo. De acordo com Bardin (2011), esse método organiza-se em torno de três polos: a pré-análise, a exploração do material e o tratamento dos resultados, a inferência e a interpretação.

A pré-análise é caracterizada pela fase da organização propriamente dita, que geralmente corresponde a três missões: a escolha dos documentos, a formulação das hipóteses ou dos objetivos e a elaboração de indicadores que fundamentam a análise final. A exploração do material refere-se a administração das técnicas no corpus do trabalho, com aplicação sistemática das decisões tomadas, enquanto o tratamento dos resultados é realizado por meio de operações estatísticas, síntese e seleção dos resultados, inferências e interpretação (BARDIN, 2011).

Estabeleceram-se os seguintes indicadores de categoria de análise:

a) Grupo de Pesquisa (GPs) em $\mathrm{Cl}$ nas Universidades Públicas Federais (UPF) da Região Nordeste certificados pelo CNPq; 
b) Proporção da produção científica dos líderes dos GPs;

c) Temáticas abordadas pelos GPs; e

d) Formas de disseminação dos resultados de pesquisas e sua tipologia.

A pesquisa teve como sujeitos os líderes dos GPs em $\mathrm{Cl}$ do DGP, restringindo-se às Universidades Publicas Federais do Nordeste brasileiro. No quadro 1, é visualizado o panorama dos grupos encontrados nos nove estados nordestinos, sem a restrição utilizada para a pesquisa.

Quadro 1 - Grupos de Pesquisa em Ciência da Informação do Nordeste do Brasil

\begin{tabular}{|c|c|c|c|}
\hline Estado & $\begin{array}{c}\text { Instituição de } \\
\text { Ensino }\end{array}$ & $\begin{array}{l}\text { Qnt } \\
\text { GPs }\end{array}$ & GPs em Cl \\
\hline \multirow{6}{*}{ Alagoas } & \multirow{6}{*}{$\begin{array}{l}\text { Universidade } \\
\text { Federal de Alagoas } \\
\text { (UFAL) }\end{array}$} & \multirow{6}{*}{06} & Gnosiologia, Ética e Informação (GEINFO) \\
\hline & & & \begin{tabular}{|c|} 
Laboratório de Estudos Métricos da Informação na \\
Web (Lab-iMetrics)
\end{tabular} \\
\hline & & & \begin{tabular}{|c}
$\begin{array}{c}\text { Laboratório de Pesquisa em Informação e Informática } \\
\text { em Saúde (LAPIIS) }\end{array}$ \\
\end{tabular} \\
\hline & & & Leitura, Biblioteca Escolar e Cidadania \\
\hline & & & $\begin{array}{c}\text { Núcleo de Estudos em Informação, Tecnologia e } \\
\text { Inovação (NESITI) }\end{array}$ \\
\hline & & & $\begin{array}{c}\text { Observatório de Estudos Interdisciplinares da } \\
\text { Informação (Observinter) }\end{array}$ \\
\hline \multirow{9}{*}{ Bahia } & \multirow{9}{*}{$\begin{array}{l}\text { Universidade } \\
\text { Federal da Bahia } \\
\quad \text { (UFBA) }\end{array}$} & \multirow{9}{*}{10} & $\begin{array}{l}\text { Competências e comportamento: processos de } \\
\text { produção, inovação e comunicação da informação } \\
\text { (COMPORTI) }\end{array}$ \\
\hline & & & $\begin{array}{c}\text { Difusão do Conhecimento e Apropriação de Saberes } \\
\text { Acesso e uso (DIFUSAS) }\end{array}$ \\
\hline & & & $\begin{array}{l}\text { Acervos manuscriptológicos, bibliográficos, } \\
\text { iconográficos, etnográficos: organização, preservaçãc } \\
\text { e interfaces das tecnologias da informação e } \\
\text { comunicação (G-Acervos) }\end{array}$ \\
\hline & & & $\begin{array}{c}\text { GEINFO Saberes e Fazeres em Informação e do } \\
\text { Conhecimento }\end{array}$ \\
\hline & & & $\begin{array}{l}\text { GEPICC-Grupo de Estudos de Políticas de } \\
\text { Informação, Comunicações e Conhecimento }\end{array}$ \\
\hline & & & $\begin{array}{c}\text { Grupo de Estudos sobre Cultura, Representação e } \\
\text { Informação Digitais (CRIDI) }\end{array}$ \\
\hline & & & $\begin{array}{l}\text { Grupo de Estudos e Pesquisa em Mediação e } \\
\text { Comunicação da Informação (GEPEMCI) }\end{array}$ \\
\hline & & & $\begin{array}{c}\text { Grupo Interinstitucional de Processos Semiótico e de } \\
\text { Design }\end{array}$ \\
\hline & & & $\begin{array}{c}\text { Laboratório de Tecnologias Informacionais e Inclusão } \\
\text { Sociodigital (LTI Digital) }\end{array}$ \\
\hline
\end{tabular}


Andreza Pereira Batista, Gabriela Belmont de Farias

Grupos de pesquisa em Ciência da Informação da região nordeste do Brasil: análise da produção, temáticas e disseminação da comunicação científica

\begin{tabular}{|c|c|c|c|}
\hline & & & $\begin{array}{l}\text { Rede Corporativa de Pesquisa e Intervenção em } \\
\qquad(\text { In)Formação }\end{array}$ \\
\hline & $\begin{array}{l}\text { SENAI/DR da Bahia } \\
\text { (SENAI/DR/BA) }\end{array}$ & 01 & Cognição, Conhecimento e Inovação \\
\hline \multirow{12}{*}{ Ceará } & \multirow{6}{*}{$\begin{array}{c}\text { Universidade } \\
\text { Federal do Ceará } \\
\text { (UFC) }\end{array}$} & \multirow{6}{*}{06} & $\begin{array}{l}\text { Competência e mediação em ambientes de } \\
\text { informação (CMAl) }\end{array}$ \\
\hline & & & Cultura, Mediação e Gestão da Informação \\
\hline & & & Estudos de Usuários da Informação \\
\hline & & & $\begin{array}{c}\text { Grupo de Pesquisa de Aplicações em Tecnologias } \\
\text { Assistivas e Usabilidade }\end{array}$ \\
\hline & & & Grupo de Pesquisa em Representação da Informação \\
\hline & & & $\begin{array}{c}\text { Tecnologias Aplicadas à Gestão e Representação da } \\
\text { Informação }\end{array}$ \\
\hline & \multirow{5}{*}{$\begin{array}{l}\text { Universidade } \\
\text { Federal do Cariri } \\
\text { (UFCA) }\end{array}$} & \multirow{5}{*}{05} & $\begin{array}{l}\text { Biblioteconomia, Extensão universitária e Mediação } \\
\text { da Informação (BEM) }\end{array}$ \\
\hline & & & Biblioteca, Informação e Sociedade (BIS) \\
\hline & & & Memória, Acervos e Patrimônio (GRUPO MAPA) \\
\hline & & & $\begin{array}{c}\text { Laboratório Interdisciplinar de Gestão e Tecnologia da } \\
\text { Informação (LAGENTI) }\end{array}$ \\
\hline & & & $\begin{array}{c}\text { SABERES - Informação e cultura, Patrimônio cultural } \\
\text { e Sustentabilidade }\end{array}$ \\
\hline & \begin{tabular}{|} 
Instituto Federal de \\
Educação, Ciência e \\
Tecnologia do \\
Ceará (IFCE)
\end{tabular} & 01 & Informação, Conhecimento e Sociedade \\
\hline Maranhão & - & 0 & - \\
\hline \multirow{10}{*}{ Paraíba } & \multirow{10}{*}{$\begin{array}{c}\text { Universidade } \\
\text { Federal da Paraíba } \\
\text { (UFPB) }\end{array}$} & \multirow{10}{*}{13} & Epistemologia Arquivística (GEPE - ARQ) \\
\hline & & & Epistemologia e Políticas de Informação \\
\hline & & & $\begin{array}{l}\text { Grupo de Estudos e Pesquisa em Cultura, } \\
\text { Informação, Memória e Patrimônio (GECIMP) }\end{array}$ \\
\hline & & & $\begin{array}{l}\text { Grupo de Estudo e Pesquisa em Sociologia e } \\
\text { Informação (GEPSI) }\end{array}$ \\
\hline & & & $\begin{array}{l}\text { Grupo de Estudos e Pesquisas em Arquivística e } \\
\text { Normas para Gestão Documental (GEPAN-GeDoc) }\end{array}$ \\
\hline & & & Da Informação e do Conhecimento \\
\hline & & & Gestão, Empreendedorismo e Informação \\
\hline & & & $\begin{array}{l}\text { Informação, Memória, Tecnologias e Sociedade } \\
\text { (iMclusoS) }\end{array}$ \\
\hline & & & Informação, Aprendizagem e Conhecimento (GIACO) \\
\hline & & & Informação e Inclusão Social \\
\hline
\end{tabular}

Inf. Inf., Londrina, v. 25, n. 2, p. 124 - 149, abr./jun. 2019. 


\begin{tabular}{|c|c|c|c|}
\hline & & & $\begin{array}{l}\text { Leitura, organização, representação, produção e uso } \\
\text { da informação }\end{array}$ \\
\hline & & & $\begin{array}{c}\text { Estudos sobre Arquitetura, Acesso, Uso e Aspectos } \\
\text { Jurídicos da Informação (Renovatio) }\end{array}$ \\
\hline & & & Web, Representação do Conhecimento e Ontologias \\
\hline & $\begin{array}{c}\text { Instituto Federal de } \\
\text { Educação, Ciência e } \\
\text { Tecnologia da } \\
\text { Paraíba (IFPB) }\end{array}$ & 01 & $\begin{array}{l}\text { Gestão de Projetos em Educação, Ciência, } \\
\text { Informação e Tecnologia (PROJECIT) }\end{array}$ \\
\hline \multirow{12}{*}{ Pernambuco } & \multirow{12}{*}{$\begin{array}{l}\text { Universidade } \\
\text { Federal de } \\
\text { Pernambuco } \\
\text { (UFPE) }\end{array}$} & \multirow{12}{*}{12} & Tecnologia da Informação (Agadê) \\
\hline & & & Estudos epistemológicos em Informação (EEI) \\
\hline & & & Imago e humanidades digitais. \\
\hline & & & Informação Tecnológica \\
\hline & & & Grupo de Trabalho Histórico Ecumênico Organizado \\
\hline & & & $\begin{array}{c}\text { Laboratório de Organização e Gestão da Informação } \\
\text { e do Conhecimento (LOGIC) }\end{array}$ \\
\hline & & & Memória e cultura escrita \\
\hline & & & Memória e Sociedade \\
\hline & & & Núcleo de Curadoria Digital \\
\hline & & & Organização e Representação do Conhecimento \\
\hline & & & Prospecção e Práxis em Gestão da Informação \\
\hline & & & Scientia \\
\hline Piauí & $\begin{array}{l}\text { Universidade } \\
\text { Estadual do Piauí } \\
\quad \text { (UESPI) }\end{array}$ & 01 & $\begin{array}{l}\text { Grupo de Estudos e Pesquisas em Biblioteconomia e } \\
\text { Ciência da }\end{array}$ \\
\hline \multirow{4}{*}{$\begin{array}{l}\text { Rio Grande } \\
\text { do Norte }\end{array}$} & \multirow{3}{*}{$\begin{array}{c}\text { Universidade } \\
\text { Federal do Rio } \\
\text { Grande do Norte } \\
\text { (UFRN) }\end{array}$} & \multirow{3}{*}{03} & $\begin{array}{c}\text { Controladoria, Governança e Tecnologia da } \\
\text { Informação: Aplicação a Processos Orientados à } \\
\text { Resultados (CGTI) }\end{array}$ \\
\hline & & & Informação na Sociedade Contemporânea \\
\hline & & & $\begin{array}{c}\text { Tecnologia e Gestão da Informação e do } \\
\text { Conhecimento }\end{array}$ \\
\hline & $\begin{array}{l}\text { Universidade } \\
\text { Federal Rural do } \\
\text { Semi-Árido } \\
\text { (UFERSA) }\end{array}$ & 01 & $\begin{array}{l}\text { Grupo de Pesquisa em Cultura, Conhecimento e } \\
\text { Inovação }\end{array}$ \\
\hline \multirow{3}{*}{ Sergipe } & \multirow{3}{*}{$\begin{array}{l}\text { Universidade } \\
\text { Federal de Sergipe } \\
\text { (UFS) }\end{array}$} & \multirow{3}{*}{03} & $\begin{array}{l}\text { Núcleo de Estudos em Mediação, Apropriação e } \\
\text { Gestão da Informação e Conhecimento (NEMAGI) }\end{array}$ \\
\hline & & & $\begin{array}{c}\text { Grupo de Pesquisa em Leitura, Escrita e Narrativa: } \\
\text { Cultura, Mediação, Apresentação Gráfica, Editoração } \\
\text { Manifestações (PLENA) }\end{array}$ \\
\hline & & & Observatório Informacional do Trabalho (OIT) \\
\hline
\end{tabular}

Inf. Inf., Londrina, v. 25, n. 2, p. 124 - 149, abr./jun. 2019. 


\begin{tabular}{|c|c|c|}
\hline \multirow{2}{*}{$\begin{array}{l}\text { Instituto Federal de } \\
\text { Educação, Ciência e } \\
\text { Tecnologia de } \\
\text { Sergipe (IFS) }\end{array}$} & \multirow{2}{*}{02} & $\begin{array}{l}\text { Grupo de Estudos e Pesquisas sobre História das } \\
\text { Bibliotecas de Ensino }\end{array}$ \\
\hline & & $\begin{array}{l}\text { Grupo de Estudos e Pesquisas sobre História das } \\
\text { Bibliotecas de Ensino }\end{array}$ \\
\hline Total de GPs & & 65 Grupos de Pesquisa \\
\hline
\end{tabular}

Fonte: elaborado pelas autoras (2019) com base em Conselho Nacional de Desenvolvimento Científico e Tecnológico ([201-]d).

Como instrumento de coleta de dados, utilizou-se o DGP do CNPq, para o levantamento do quantitativo de grupos a serem analisado, onde foram estabelecidos os campos "Consulta por" e "Situação", sendo definidos "grupo" e "certificado", respectivamente, em conjunto com os seguintes filtros para restrição de acordo com os objetivos da pesquisa:

a) Região (Nordeste);

b) Grande Área (Ciências Sociais Aplicadas - predominante no grupo); e

c) Área (Ciência da Informação - relacionada à linha de pesquisa).

No diretório, foram identificados a instituição, o nome do grupo, líder e $2^{-}$ líder (havendo sua existência), linhas de pesquisa, data de criação e atualização e área predominante. Essas informações auxiliaram a caracterizar o $\mathrm{GP} \mathrm{em} \mathrm{Cl}$ no âmbito das Ciências Sociais Aplicadas.

Tendo em vista que o DGP considera a produção individual dos membros de cada grupo, para verificar os meios e formas de comunicação científica, definiu-se que seriam examinados somente os líderes.

Assim, foi realizada a pesquisa por autor dentro da base WOS, acessada pelo Portal de Periódicos da Coordenação de Aperfeiçoamento de Pessoal de Nível Superior (CAPES). A busca levou em consideração os campos: 'Autor' (uma vez que a produção dos grupos dentro do DGP é atribuída a cada pesquisador) e 'Tempo' (de 1993 a 2016 - anos nos quais foram realizados os censos pelo DGP).

Tomou-se como base os documentos indexados na Principal Coleção da WOS, não restringindo nenhum tipo específico de produção, idioma ou instituição. O único critério estabelecido foi à participação do líder no arquivo recuperado pela base. A coleta dos dados no DGP e na WOS sucedeu-se entre setembro e outubro de 2019, não regressando-se para o autor(a) após realizada 
a busca ${ }^{3}$.

A partir das diretrizes estabelecidas, no DGP foram encontrados 303 GPs em Cl. Desse montante, 65 GPs são da Região Nordeste. Após a exportação dos dados, retirou-se da quantidade total: quatro Institutos Federais, um GP no Senai da Bahia, dois na Estadual do Piauí e um na Estadual da Paraíba, admitindo-se, portanto, 59 grupos para a tabulação.

Foram verificados que sete grupos estavam desatualizados (há mais de 12 meses) e dois grupos encontravam-se em preenchimento. Logo, adotou-se um total de 50 GPs para verificação dentro da WOS. Nestes, foram contabilizados 84 líderes, nos quais realizou-se a busca nominal de cada autor na WOS, constatando-se, ao final, 26 autores com produções científicas.

\section{ANÁLISE E INTERPRETAÇÃO DOS DADOS}

Os cinco indicadores estabelecidos para as categorias de análise apresentados na sessão anterior guiaram a coleta dos dados dentro do DGP e da WOS. Para melhor compreensão estabeleceu-se as categorias em quantitativo e qualitativo conforme quadro 2.

\section{Quadro 2 - Categoria de análise conforme sua abordagem}

\begin{tabular}{|c|l|}
\hline Abordagem & \multicolumn{1}{|c|}{ Categoria de Análise } \\
\hline Quantitativa & $\begin{array}{l}\text { - GPs em Cl nas UPF da Região Nordeste certificados pelo CNPq; } \\
\text { - Proporção da produção científica dos líderes dos GPs. }\end{array}$ \\
\hline Qualitativa & $\begin{array}{l}\text { - Temáticas abordadas pelos GPs; } \\
\text { - Formas de disseminação dos resultados de pesquisas e sua } \\
\text { tipologia. }\end{array}$ \\
\hline
\end{tabular}

Fonte: elaborado pelas autoras (2019).

Nessa perspectiva, a categoria - GPs em Cl nas UPF da Região Nordeste certificado pelo CNPq, corresponde ao total de 50 GPs e 84 líderes conforme a coleta de dados e as retificações descritas na seção anterior, compreendendo: $0,64 \%$ dos 7.713 GPs no Nordeste; $0,93 \%$ dos $14 \%$ da grande

${ }^{3}$ Pela Web of Science ser uma base atualizada constantemente, há a possibilidade dos resultados obtidos durante a coleta apresentarem diferenças e acréscimos se realizadas em outros períodos, gerando modificações nos somatórios dos dados colhidos. 
área 'Sociais Aplicadas' (5.363 GPs); e 19,30\% dos 259 GPs da área da Cl. Vale ressaltar que não foi observado grupos na $\mathrm{Cl}$ no estado do Maranhão, apesar de possui 493 GPs cadastrados diretório. Sendo assim para fins da análise serão utilizados os quantitativos apresentados no quadro 3.

Quadro 3 - Líderes dos Grupos de Pesquisa em Cl no Nordeste

\begin{tabular}{|c|c|c|}
\hline UPF & GPs & Liderança \\
\hline \multirow{6}{*}{$\begin{array}{l}\stackrel{\vec{\leftarrow}}{\leftrightarrows} \\
\stackrel{\leftrightarrows}{J}\end{array}$} & GEINFO & $\begin{array}{l}\text { Israel Alexandria Costa } \\
\text { Genildo Ferreira da Silva }\end{array}$ \\
\hline & Lab-iMetrics & Ronaldo Ferreira de Araújo \\
\hline & LAPIIS & $\begin{array}{l}\text { Francisca Rosaline Leite Mota } \\
\text { Maria Lucelia da Hora Sales }\end{array}$ \\
\hline & Leitura, Biblioteca Escolar e Cidadania & $\begin{array}{l}\text { Nelma Camelo de Araújo } \\
\text { Clarice Vanderlei Ferraz }\end{array}$ \\
\hline & NESITI & $\begin{array}{c}\text { Francisca Rosaline Leite Mota } \\
\text { Marcos Aurélio Gomes }\end{array}$ \\
\hline & Observinter & Edivânio Duarte de Souza \\
\hline \multirow{8}{*}{$\begin{array}{l}\text { 咅 } \\
\text { 号 }\end{array}$} & COMPORTI & $\begin{array}{l}\text { Maria Isabel de Jesus Sousa } \\
\text { José Carlos Sales dos Santos }\end{array}$ \\
\hline & DIFUSAS & $\begin{array}{l}\text { Hildenise Ferreira Novo } \\
\text { Ivana Aparecida Borges Lins }\end{array}$ \\
\hline & G-Acervos & Zeny Duarte de Miranda \\
\hline & GEPICC & $\begin{array}{c}\text { Francisco José Aragão Pedroza Cunha } \\
\text { Maria Carolina Santos de Souza }\end{array}$ \\
\hline & CRIDI & $\begin{array}{c}\text { Ricardo Sodré Andrade } \\
\text { Adriana Lúcia Cox Hollós }\end{array}$ \\
\hline & $\begin{array}{c}\text { Grupo Interinstitucional de Processos } \\
\text { Semiótico e de Design }\end{array}$ & $\begin{array}{l}\text { Lídia Maria Batista Brandão Toutain } \\
\text { Jean Claude Novaes de Almeida }\end{array}$ \\
\hline & LTI Digital & Barbara Coelho Neves \\
\hline & $\begin{array}{l}\text { Rede Coorporativa de Pesquisa e } \\
\text { Intervenção em (In)Formação }\end{array}$ & $\begin{array}{l}\text { Maria Inês Corrêa Marques } \\
\text { Carollina Carvalho Ramos de Lima }\end{array}$ \\
\hline \multirow{5}{*}{$\begin{array}{l}\text { U } \\
\text { 岇 }\end{array}$} & CMAI & $\begin{array}{l}\text { Maria Giovanna Guedes Farias } \\
\text { Gabriela Belmont de Farias }\end{array}$ \\
\hline & Cultura, Mediação e Gestão da Informação & $\begin{array}{l}\text { Lídia Eugenia Cavalcante } \\
\text { Jefferson Veras Nunes }\end{array}$ \\
\hline & Estudos de Usuários da Informação & $\begin{array}{c}\text { Maria de Fátima Oliveira Costa } \\
\text { Jefferson Veras Nunes }\end{array}$ \\
\hline & $\begin{array}{l}\text { Grupo de Pesquisa em Representação da } \\
\text { Informação }\end{array}$ & $\begin{array}{l}\text { Virgínia Bentes Pinto } \\
\text { Heliomar Cavati Sobrinho }\end{array}$ \\
\hline & $\begin{array}{l}\text { Tecnologias Aplicadas à Gestão e } \\
\text { Representação da Informação }\end{array}$ & Hamilton Rodrigues Tabosa \\
\hline \multirow{4}{*}{$\begin{array}{l}\overleftarrow{\circlearrowleft} \\
\stackrel{\square}{\supset}\end{array}$} & BEM & Elieny do Nascimento Silva \\
\hline & BIS & Maria Cleide Rodrigues \\
\hline & LAGENTI & David Vernon Vieira \\
\hline & SABERES & $\begin{array}{l}\text { Deise Santos do Nascimento } \\
\text { Vitória Gomes Almeida }\end{array}$ \\
\hline
\end{tabular}


Andreza Pereira Batista, Gabriela Belmont de Farias

Grupos de pesquisa em Ciência da Informação da região nordeste do Brasil: análise da produção, temáticas e disseminação da comunicação científica

\begin{tabular}{|c|c|c|}
\hline \multirow{11}{*}{$\begin{array}{l}\frac{\infty}{0} \\
\stackrel{0}{丂}\end{array}$} & GEPE - ARQ & $\begin{array}{l}\text { Luiz Eduardo Ferreira da Silva } \\
\text { Danielle Alves de Oliveira }\end{array}$ \\
\hline & Epistemologia e Políticas de Informação & $\begin{array}{c}\text { Isa Maria Freire } \\
\text { Gustavo Henrique de Araújo Freire }\end{array}$ \\
\hline & GECIMP & $\begin{array}{c}\text { Bernardina Maria Juvenal Freire de Oliveira } \\
\text { Maria Nilza Barbosa Rosa }\end{array}$ \\
\hline & GEPSI & $\begin{array}{c}\text { Edvaldo Carvalho Alves } \\
\text { Gisele Rocha Côrtes }\end{array}$ \\
\hline & GEPAN-GeDoc & $\begin{array}{l}\text { Rosa Zuleide Lima de Brito } \\
\text { Julianne Teixeira e Silva }\end{array}$ \\
\hline & iMclusoS & $\begin{array}{l}\text { Izabel França de Lima } \\
\text { Henry Poncio Cruz de Oliveira }\end{array}$ \\
\hline & GIACO & $\begin{array}{l}\text { Alzira Karla Araújo da Silva } \\
\text { Emeide Nóbrega Duarte }\end{array}$ \\
\hline & Informação e Inclusão Social & $\begin{array}{c}\text { Isa Maria Freire } \\
\text { Gustavo Henrique de Araújo Freire }\end{array}$ \\
\hline & $\begin{array}{l}\text { Leitura, organização, representação, } \\
\text { produção e uso da informação }\end{array}$ & $\begin{array}{l}\text { Dulce Amelia de Brito Neves } \\
\text { Maria Elizabeth Baltar Carneiro de }\end{array}$ \\
\hline & Renovatio & $\begin{array}{c}\text { Francisca Arruda Ramalho } \\
\text { Marckson Roberto Ferreira de Sousa }\end{array}$ \\
\hline & $\begin{array}{c}\text { Web, Representação do Conhecimento e } \\
\text { Ontologias }\end{array}$ & $\begin{array}{l}\text { Guilherme Ataíde Dias } \\
\text { Edberto Ferneda }\end{array}$ \\
\hline \multirow{10}{*}{$\begin{array}{l}\frac{w}{0} \\
\stackrel{0}{丂}\end{array}$} & Agadê & Bruno Tenório Ávila \\
\hline & EEI & $\begin{array}{c}\text { Májory Karoline Fernandes de Oliveira } \\
\text { Miranda } \\
\text { Marcos Galindo Lima }\end{array}$ \\
\hline & Imago e humanidades digitais & $\begin{array}{l}\text { Májory Karoline Fernandes de Oliveira Miranda } \\
\text { Diego Andres Salcedo }\end{array}$ \\
\hline & LOGIC & $\begin{array}{l}\text { Renato Fernandes Corrêa } \\
\text { André Felipe de Albuquerque Fell }\end{array}$ \\
\hline & Memória e cultura escrita & $\begin{array}{l}\text { Marlos de Barros Pessoa } \\
\text { Gilda Maria Whitaker Verri }\end{array}$ \\
\hline & Memória e Sociedade & $\begin{array}{c}\text { Marcos Galindo Lima } \\
\text { Májory Karoline Fernandes de Oliveira }\end{array}$ \\
\hline & Núcleo de Curadoria Digital & $\begin{array}{l}\text { Aureliana Lopes de Lacerda Tavares } \\
\text { Sandra de Albuquerque }\end{array}$ \\
\hline & $\begin{array}{l}\text { Organização e Representação do } \\
\text { Conhecimento }\end{array}$ & Fábio Assis Pinho \\
\hline & $\begin{array}{l}\text { Prospecção e Práxis em Gestão da } \\
\text { Informação }\end{array}$ & $\begin{array}{l}\text { Nadi Helena Presser } \\
\text { Edilene Maria da Silva }\end{array}$ \\
\hline & Scientia & $\begin{array}{c}\text { Fábio Mascarenhas e Silva } \\
\text { Raimundo Nonato Macedo dos Santos }\end{array}$ \\
\hline \multirow{2}{*}{ 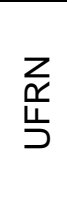 } & Informação na Sociedade Contemporânea & $\begin{array}{l}\text { Luciana de Albuquerque Moreira } \\
\text { Jacqueline Aparecida de Souza }\end{array}$ \\
\hline & $\begin{array}{l}\text { Tecnologia e Gestão da Informação e do } \\
\text { Conhecimento }\end{array}$ & $\begin{array}{l}\text { Andréa Vasconcelos Carvalho } \\
\text { Fernando Luiz Vechiato }\end{array}$ \\
\hline 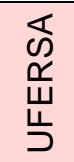 & $\begin{array}{l}\text { Grupo de Pesquisa em Cultura, } \\
\text { Conhecimento e Inovação }\end{array}$ & $\begin{array}{l}\text { Mário Gaudêncio } \\
\text { Christiane Fernandes dos Santos }\end{array}$ \\
\hline
\end{tabular}

Inf. Inf., Londrina, v. 25, n. 2, p. 124 - 149, abr./jun. 2019. 


\begin{tabular}{|c|c|c|}
\hline \multirow{3}{*}{$\leftrightarrows$} & NEMAGI & Martha Suzana Cabral Nunes \\
\cline { 2 - 3 }$\leftrightarrows$ & PLENA & $\begin{array}{c}\text { Valeria Aparecida Bari } \\
\text { Glêyse Santos Santana }\end{array}$ \\
\cline { 2 - 3 } & OIT & Sérgio Luiz Elias de Araújo \\
\hline
\end{tabular}

Fonte: elaborado pelas autoras (2019) baseado nos dados do Conselho Nacional de Desenvolvimento Científico e Tecnológico ([201-]d).

Não foi possível a verificação dos dados oficiais relativos aos líderes dos GPs no diretório, portanto, infere-se que o total ligado aos líderes analisados no quadro 3 permite a percepção da liderança colaborativa na área de $\mathrm{Cl}$, onde 39 GPs dos 50 demonstrado dispõe de dois líderes (78\%).

Com efeito, essa percepção vem de encontro a um dos objetivos do DGP, que é exatamente ser um instrumento de troca e intercâmbio de informações, e quando feito no contexto de um GP, possibilita a produção e renovação dos saberes existentes de modo mais substancial para a área, aqui representada pela Cl.

Na categoria - Proporção da produção científica dos líderes dos GPs, observou-se que dos 84 líderes somente 26 deles possuem publicações científicas indexadas na WOS, totalizando 172 publicações. Esse dado nos leva a refletir sobre o baixo número de publicações de impacto internacional nas bases de dados de grande alcance na área da Cl. Claro que deve-se levar em consideração os diversos critérios aos quais essas bases possuem para serem indexadas na WOS, o que pode-se apontar como fator para esse índice baixo de líderes com produções de impacto internacional.

O DGP aponta os líderes como responsáveis pela coordenação e planejamento das atividades do grupo, e aqui podemos indicar como encarregados igualmente por conduzir as produções e posteriores publicações de comunicações científicas a partir do que é discutido no GP, com seus membros envolvidos permanentemente com as atividades de pesquisa, em um cenário ideal.

Todavia, sabe-se que não essa não corresponde a realidade visualizada em parte dos grupos, de modo que é interessante trazer a tona uma reflexão acerca da quantidade versus qualidade de produções científicas, pois ao mesmo tempo que há a necessidade das publicações para a continuidade do fazer 
científico, é preciso atentar para os estudos divulgados serem substanciais para a área, a fazendo desenvolver-se.

$\mathrm{Na}$ categoria - Temáticas abordadas pelos GPs, foi perceptível a presença do termo "informação" como abordagem central das linhas de pesquisa dos grupos, o que não denota surpresa visto a área nos quais eles encontramse. Os GPs possuem cerca de três linhas de pesquisa, que retratam suas vertentes de estudo. Essa representação do termo "informação" dentro dessas linhas simboliza a atenção dos grupos no estudo das temáticas - gestão da informação, tecnologia da informação e mediação da informação - com sendo as temáticas mais recorrentes. Corrobora-se com o que foi descrito, a figura 2, que traz uma nuvem de palavras onde os termos com maior peso localizam-se em destaque.

\section{Figura 2 - Temáticas predominantes nos GPs a partir das linhas de pesquisa}

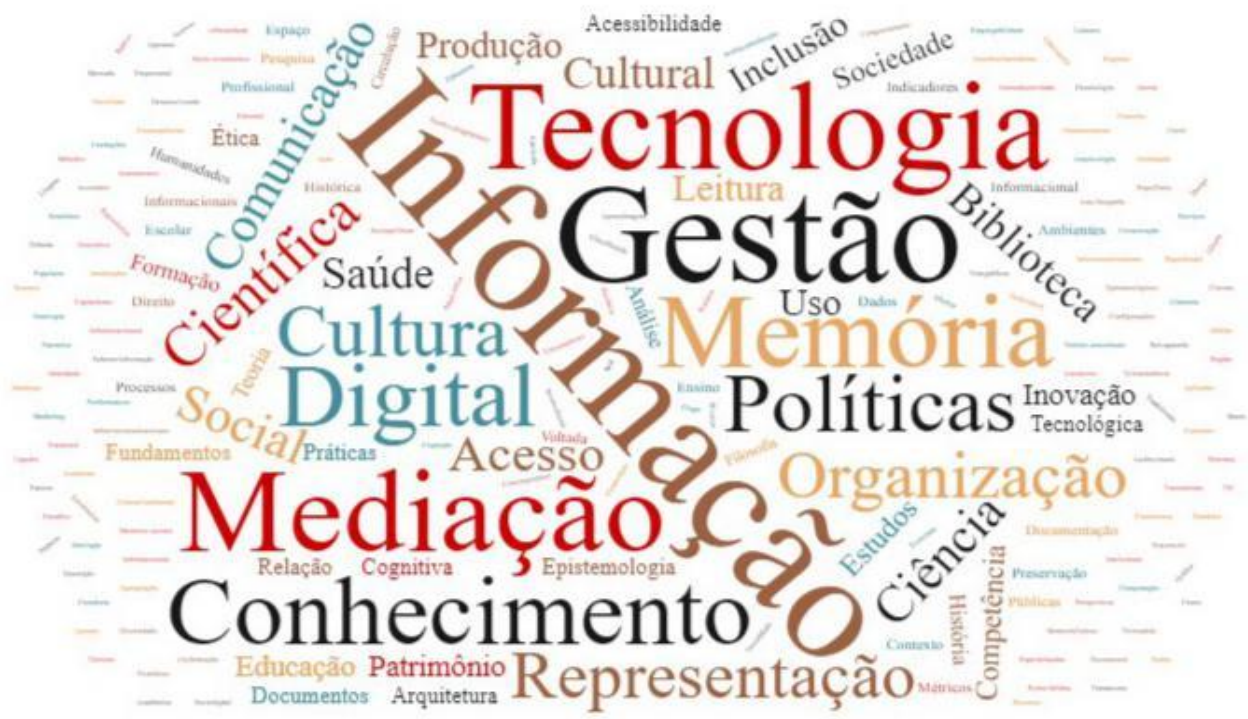

Fonte: elaborado pelas autoras (2019).

No mais, os termos "gestão", "tecnologia" e "mediação" seguem como palavras expressivas presentes nas linhas de pesquisa, onde compreende-se sua relação direta com o que vem sendo trabalho dentro da Cl. É inegável o papel das tecnologias para as sociedades modernas, associadas a gestão das informações provenientes de seu uso massivo, produzem fenômenos sociais constantes.

Para a composição da nuvem de palavras, foram retiradas todas as 
palavras sem peso semântico para a análise, tais como "que", "e" e "e/ou". Além disso, todos os termos que estavam no plural foram retiradas e seu peso incorporado ao termo no singular, quando este já encontrava-se presente em outras linhas de pesquisa, para evitar duplicação de palavras. Por conseguinte, manteve-se o termo no plural nos casos em que ela estava presente em todos os contextos dessa forma, como exemplo "atividades", ou que apareceu somente uma vez, como "configurações".

Sob outro enfoque, os estudos publicados por esses líderes acompanham o que foi constatado nos termos predominantes nas linhas de pesquisa. $O$ gráfico 5 apresenta as áreas temáticas cadastradas em cada produção indexada na WOS.

\section{Gráfico 5 - Temáticas predominantes nas produções}

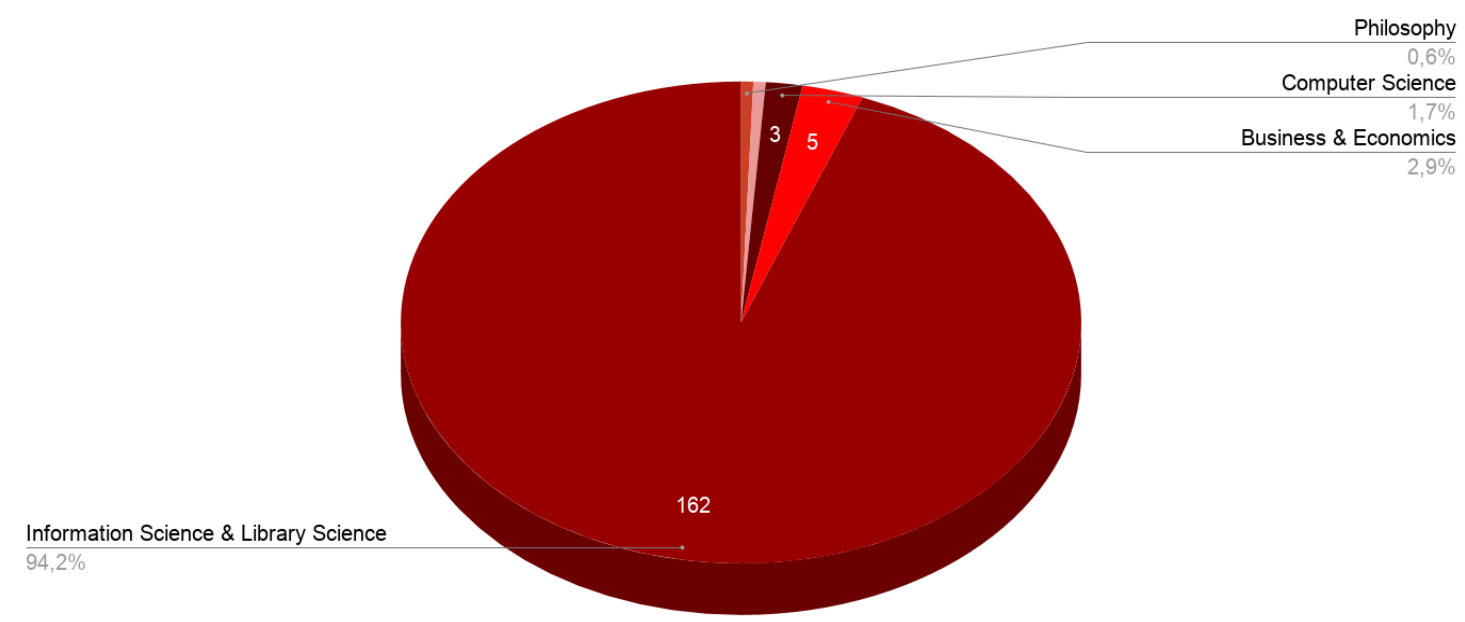

Fonte: elaborado pelas autoras (2019).

Da proporção total de produções científicas, é visualizado que a área Information Science \& Library Science é predominante, com 162 dos 172 documentos retornados durante a busca, um total de $94,2 \%$. Esse resultado era esperado, haja vista que a probabilidade dos líderes analisados pertencerem a áreas ligadas a $\mathrm{Cl}$ é alta. Contudo, a presença de publicações em outras áreas assinala o caráter interdisciplinar dos grupos de pesquisa, e até mesmo da própria $\mathrm{Cl}$, já visualizado brevemente na figura 2 .

Ademais, na categoria de análise - Formas de disseminação dos resultados de pesquisas e sua tipologia, foi observado que todos os líderes 
com produção utilizam-se massivamente os periódicos científicos nacionais, mas há presença de publicação em revistas internacionais para comunicar. Isto posto, decidiu-se acrescentar a proporção de publicação desses pesquisadores em cada periódico encontrado na WOS, no gráfico 6.

\section{Gráfico 6 - Periódicos científicos por quantidade de publicações}

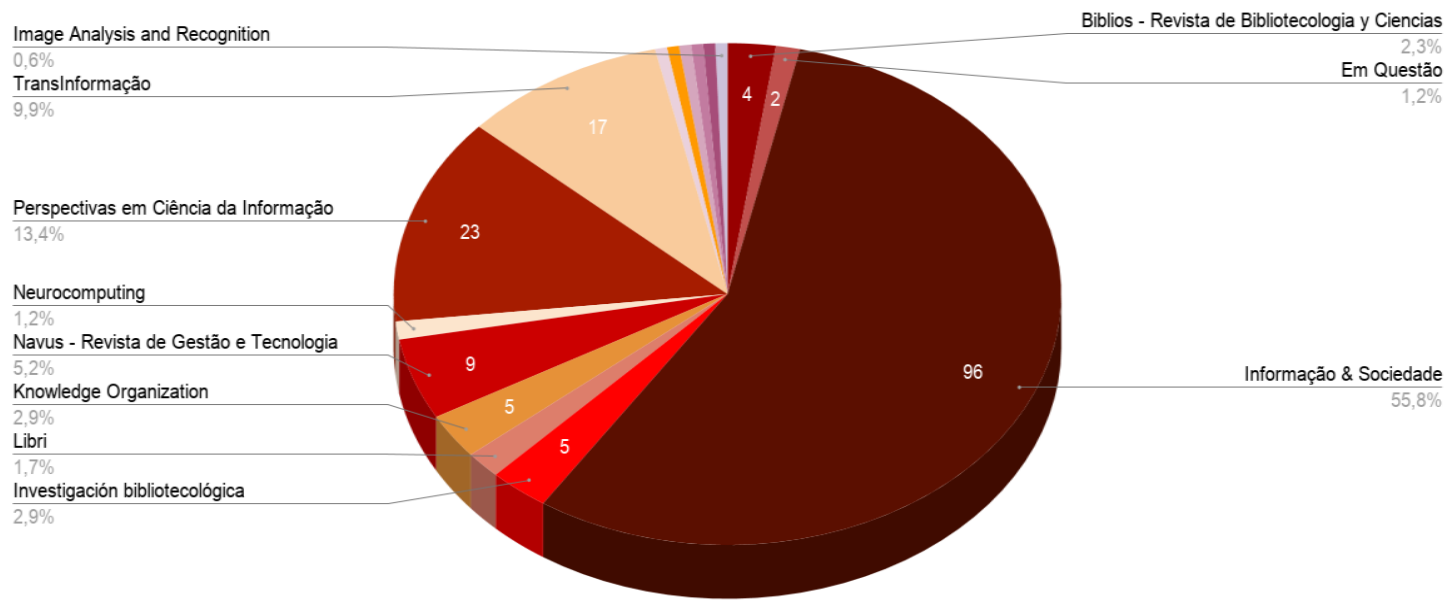

Fonte: elaborado pelas autoras (2019).

É notável que o quantitativo de publicações dos líderes concentram-se significativamente no periódico Informação \& Sociedade: Estudos, representando $55,8 \%$ do total de 172 , o que corresponde a 96 documentos. As publicações em revistas internacionais ainda são baixas, porém presente, tendo com principais periódicos o Knowledge Organization e Investigación Bibliotecológica, ambas com 2,9\%.

Apesar de não configurar-se como foco deste artigo, cabe salientar que o periódico Informação \& Sociedade: Estudos possui classificação Qualis Capes ${ }^{4}$ A1 (mais elevado no estrato de qualidade), na área da Comunicação e Informação, assim como os periódicos Perspectivas em Ciência da Informação e Transinformação, responsáveis respectivamente por 13,4\% e 9,9\% da produção identificada, o que demonstra o alto nível desses veículos no âmbito da pesquisa científica, principalmente na pós-graduação.

\footnotetext{
${ }^{4}$ De acordo com a Coordenação de Aperfeiçoamento de Pessoal do Ensino Superior ([201-]), o Qualis Periódicos é um sistema usado para classificar a produção científica dos programas de pós-graduação, referente aos artigos publicados em periódicos científicos, recebendo os estratos indicativos de qualidade A1; A2; B1; B2; B3; B4; B5 e C, nas classificações 2010-2012 e 2013-2016.
} 
Com relação à tipologia da produção científica, verificou que a mais utilizada pelos 26 líderes dos grupos está no formato de artigos científicos, com $60 \%$ do total recuperado de 1993 a 2016, seguidos de materiais editoriais, com cerca de $35 \%$. O gráfico 7 traz a presença destes dados citados, acompanhado dos proceddings papers e book review.

\section{Gráfico 7 - Tipos de produção utilizadas por líderes de GPs}

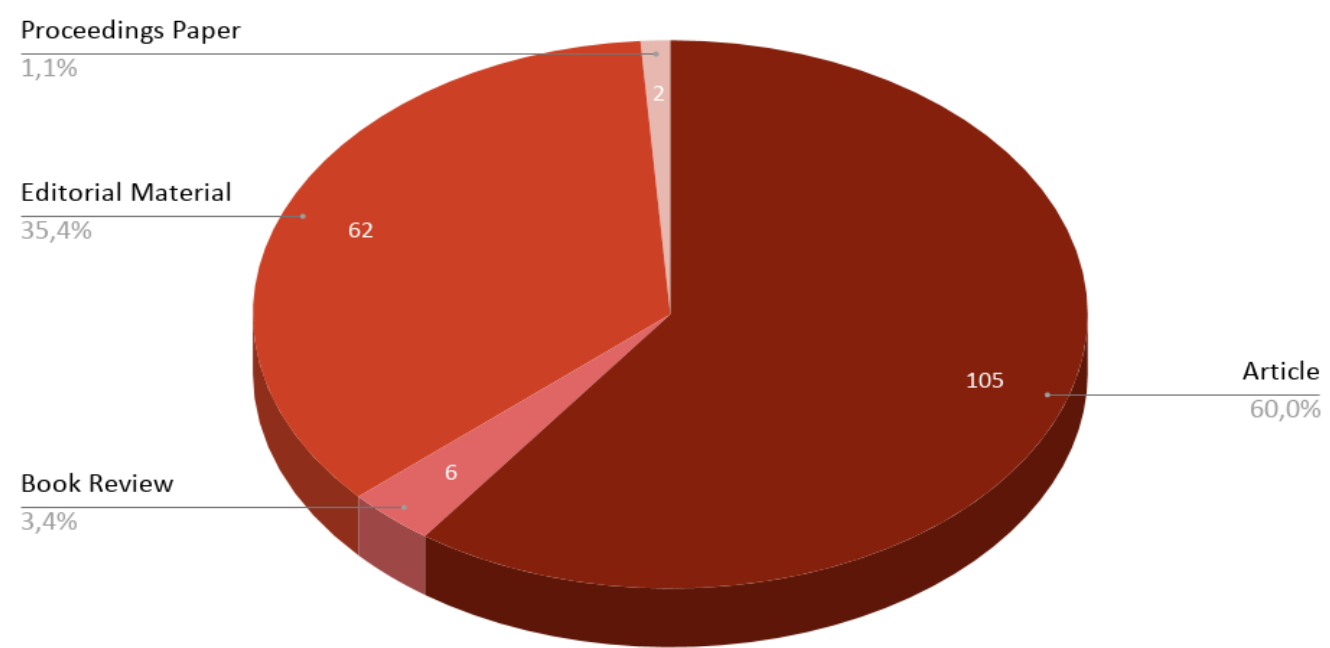

Fonte: elaborado pelas autoras (2019).

O uso de artigos científicos como principal ferramenta de comunicação pelos líderes dos GPs pode ser entendido como tendência comum no contexto acadêmico-científico, visto sua característica rápida de disseminação e acesso, bem como sua replicação e (re)uso, das informações vinculadas a essas tipologias, contribuindo de forma explícita para o desenvolvimento no campo de conhecimento.

Por fim, os gráficos e resultados propostos permitem inferir que os grupos de pesquisa do Nordeste encontram-se focados em pesquisas relacionadas principalmente na gestão, mediação e tecnologia da informação, onde os principais veículos utilizados para disseminação de tais estudos são os artigos científicos, reforçando a tendência da comunidade acadêmica, uma vez que periódicos possuem alcance mais rápido comparado a outras formas de comunicação. 


\section{CONSIDERAÇÕES FINAIS}

Os grupos de pesquisa podem ser classificados como um dos núcleos centrais na caracterização do cenário da pesquisa brasileira, onde visualiza-se contribuições e colaborações entre pesquisadores e destes com a sociedade que o cercam. Desse modo, buscou-se neste artigo estabelecer as temáticas nas quais esses grupos de pesquisa pertencentes a Região Nordeste, encontram-se alicerçados.

A partir da análise dos dados, vê-se que os grupos focam suas linhas de pesquisa no estudo da gestão, mediação e tecnologia da informação, e suas diversas possibilidades, com suas produções científicas convergentes com esse panorama, confirmando a aplicabilidade daquilo estudado pelo GP. As produções de autoria ou coautoria dos líderes dos grupos correspondem a, em sua maioria, artigos científicos em revistas especializadas. Esse tipo de comunicação ainda é o mais utilizado para atingir de forma rápida o objetivo central das publicações científicas: a disseminação de estudos.

Todavia, para que tais propósitos sejam atingidos os pesquisadores precisam produzir, o que, levando-se em consideração o somatório dos líderes dos grupos (84), vê-se que o índice daqueles que publicam em periódicos indexados na WOS ainda é pequeno. Constata-se, também, que poucos pesquisadores possuem muitas publicações e muitos pesquisadores com nenhuma, o que pode vir a ser um indicativo do domínio de algumas instituições de ensino nas pesquisas científicas em $\mathrm{Cl}$.

Para mais, compreende-se que as UPF da Nordeste brasileiro apresentam produções de peso indexadas na Web of Science, demonstrando o engajamento de pesquisadores brasileiros em produzir conhecimento de qualidade e respaldo para utilização tanto nacional quanto internacionalmente. A internacionalização dos GPs em $\mathrm{Cl}$ no que concerne a suas publicações científicas ainda é baixa ao analisar-se o quantitativo total dos grupos presentes no Nordeste do Brasil.

Apesar dessas produções estarem presentes em bases de impacto, os dados demonstram que há um caminho ainda a ser percorrido para que as 
produções científicas dos GPs passem a ter maior expressão em bases como a analisada, contribuindo para o desenvolvimento da própria comunidade acadêmica, especialmente na área da Ciência da Informação e trazendo maiores investimentos em estudos de caráter científico, em que, por conseguinte, trazem progressos para a sociedade.

\section{REFERÊNCIAS}

BARDIN, Laurence. Análise de conteúdo. São Paulo: Edições 70, 2011.

CLARIVATE ANALYTICS. Web of Science Group. A pesquisa no Brasil: promovendo a excelência. [S.I: s. n.], 2019. 42 p. Análise preparada para a CAPES pelo Grupo Web of Science.

CONSELHO NACIONAL DE DESENVOLVIMENTO CIENTÍFICO E TECNOLÓGICO (CNPq). Diretório dos Grupos de Pesquisa no Brasil Lattes. Bases censitárias ou Censo do DGP. [Brasília], [201-]a. Disponível em: https://bityli.com/s8u7b. Acesso em: 19 nov. 2019.

CONSELHO NACIONAL DE DESENVOLVIMENTO CIENTÍFICO E TECNOLÓGICO (CNPq). Diretório dos Grupos de Pesquisa no Brasil Lattes. Base corrente do DGP. [Brasília], [201-]b. Disponível em: https://bityli.com/uVa7S. Acesso em: 19 nov. 2019.

CONSELHO NACIONAL DE DESENVOLVIMENTO CIENTÍFICO E TECNOLÓGICO (CNPq). Diretório dos Grupos de Pesquisa no Brasil Lattes. Censos realizados. [Brasília], [201-]c. Disponível em: http://lattes.cnpq.br/web/dgp/ censos-realizados/. Acesso em: 16 nov. 2019.

CONSELHO NACIONAL DE DESENVOLVIMENTO CIENTÍFICO E TECNOLÓGICO (CNPq). Diretório dos Grupos de Pesquisa no Brasil Lattes. Consulta parametrizada. [Brasília], [201-]d. Disponível em: http://dgp.cnpq.br/dgp/ faces/consulta/consulta_parametrizada.jsf. Acesso em: 16 nov. 2019.

CONSELHO NACIONAL DE DESENVOLVIMENTO CIENTÍFICO E TECNOLÓGICO (CNPq). Diretório dos Grupos de Pesquisa no Brasil Lattes. Grupo de pesquisa. [Brasília], [201-]e. Disponível em: https://bityli.com/wecVw. Acesso em: 16 nov. 2019.

CONSELHO NACIONAL DE DESENVOLVIMENTO CIENTÍFICO E TECNOLÓGICO (CNPq). Diretório dos Grupos de Pesquisa no Brasil Lattes. Líder de grupo de pesquisa. [Brasília], [201-]f. Disponível em: https://bityli.com/2H13y. Acesso em: 16 nov. 2019. 
CONSELHO NACIONAL DE DESENVOLVIMENTO CIENTÍFICO E TECNOLÓGICO (CNPq). Diretório dos Grupos de Pesquisa no Brasil Lattes. Linhas de pesquisa. [Brasília], [201-]g. Disponível em: https://bityli.com/q3poP. Acesso em: 16 nov. 2019.

CONSELHO NACIONAL DE DESENVOLVIMENTO CIENTÍFICO E TECNOLÓGICO (CNPq). Diretório dos Grupos de Pesquisa no Brasil Lattes. Painel DGP. [Brasília], 2016a. Disponível em: http://lattes.cnpq.br/web/dgp/painel-dgp/. Acesso em: 19 nov. 2016.

CONSELHO NACIONAL DE DESENVOLVIMENTO CIENTÍFICO E TECNOLÓGICO (CNPq). Diretório dos Grupos de Pesquisa no Brasil Lattes. Produção C, T\&A. [Brasília], 2016b. Disponível em: http://lattes.cnpq.br/web/dgp/producao-c-t-al. Acesso em: 19 nov. 2019.

CONSELHO NACIONAL DE DESENVOLVIMENTO CIENTÍFICO E TECNOLÓGICO (CNPq). Diretório dos Grupos de Pesquisa no Brasil Lattes. Produção C, T\&A do grupo de pesquisa. [Brasília], [201-]h. Disponível em: https://bityli.com/oGMOA. Acesso em: 16 nov. 2019.

CONSELHO NACIONAL DE DESENVOLVIMENTO CIENTÍFICO E TECNOLÓGICO (CNPq). Diretório dos Grupos de Pesquisa no Brasil Lattes. Objetivo. [Brasília], [201-]i. Disponível em: http://lattes.cnpq.br/web/dgp/objetivos/. Acesso em: 16 nov. 2019.

CONSELHO NACIONAL DE DESENVOLVIMENTO CIENTÍFICO E TECNOLÓGICO (CNPq). Diretório dos Grupos de Pesquisa no Brasil Lattes. 0 que contêm as bases. [Brasília], [201-]j. Disponível em: http://lattes.cnpq.br/web/ dgp/o-que-contem-as-bases/. Acesso em: 16 nov. 2019.

COORDENAÇÃO DE APERFEIÇOAMENTO DE PESSOAL DE NÍVEL SUPERIOR (Brasil). Plataforma Sucupira. Qualis. [Brasília], [201-]. Disponível em: https://sucupira.capes.gov.br/sucupira/public/index.jsf\#. Acesso em: 01 jun. 2020.

DEUS, Jorge Dias de (org.). A crítica da ciência: sociologia e ideologia da ciência. 2. ed. Rio de Janeiro: Zahar, 1979.

DROESCHER, Fernanda Dias; SILVA, Edna Lúcia da. O pesquisador e a produção científica. Perspectivas em Ciência da Informação, v.19, n.1, p.170-189, jan./mar. 2014. Disponível em: https://bityli.com/×3hN9. Acesso em: 16 nov. 2019.

LOPES, Eliezer Mendes; LOBO, Deisiré Amaral. Características dos Grupos de Pesquisa da Universidade Federal do Rio Grande (FURG) cadastrados no Diretório de Grupos de Pesquisa do Brasil (DGP/CNPq). BIBLOS, [s.I.], v. 30, n. 1, p. 81-103, nov. 2016. Disponível em: https://periodicos.furg.br/biblos/article/view/5783. Acesso em: 16 nov. 2019. 
PRODANOV, Cleber Cristiano; FREITAS, Ernani Cesar de. Metodologia do trabalho científico: métodos e técnicas da pesquisa e do trabalho acadêmico. 2. ed. Novo Hamburgo: Feevale, 2013. Disponível em: https://bityli.com/C03tZ. Acesso em: 19 nov. 2019.

\title{
RESEARCH GROUPS IN INFORMATION SCIENCE IN THE NORTHEAST REGION OF BRAZIL: ANALYSIS OF PRODUCTION, THEMES AND DISSEMINATION IN SCIENTIFIC COMMUNICATION.
}

\begin{abstract}
Introduction: Research in the context of Brazilian scientific production is evident through research groups, especially those registered with the Conselho Nacional de Desenvolvimento Científico e Tecnológico. These groups are linked to teaching and research institutions, in particular the Federal Public Universities. In view of this, the article has as its starting questions: what are the main themes of the research groups in Information Science in the Northeast of Brazil and what are the means of communication most used by the leaders of the groups for the dissemination of scientific productions? Objective: to present the scenario of the production of Northeastern Research Groups in Information Science, registered in the Diretório dos Grupos de Pesquisa no Brasil of $\mathrm{CNPq}$, their main thematic approaches and the means of communication used. Methodology: applies the case study as a method, using the Diretório Central dos Grupos de Pesquisa as a tool for data collection and the productions published by the group leaders in the Web of Science database and the Content Analysis methodology for analysis. Results: it points out that the Northeast Information Science Research Groups are focused on research related to the themes: management, mediation and information technology, using articles in scientific journals to disseminate their research. Conclusions: Northeastern Research Groups have quality scientific publications and published in journals with Qualis/Capes, demonstrating the researchers' commitment to producing knowledge for the (re)use by the academic community, and consequently, for society.
\end{abstract}

Descriptors: Information Science. Scientific Communication. Information management. Research Groups. Scientific production.

\section{GRUPOS DE INVESTIGACIÓN EN CIENCIAS DE LA INFORMACIÓN EM EL NORESTE DE BRASIL: ANÁLISIS DE PRODUCCIÓN, TEMAS Y DIFUSIÓN EN LA COMUNICACIÓN CIENTÍFICA.}

\section{RESUMEN}

Introducción: La producción científica brasileña se promueve a través de estudios desarrollados por grupos de investigación, especialmente aquellos registrados en el Conselho Nacional de Desenvolvimento Científico e Tecnológico. Estos grupos están 
vinculados a instituciones de enseñanza e investigación, en particular las universidades públicas federales. En vista de esto, el artículo tiene como preguntas iniciales: ¿cuáles son los temas principales de los grupos de investigación en Ciencias de la Información en el noreste de Brasil y cuáles son los medios de comunicación más utilizados por los líderes de los grupos para la difusión de producciones científicas? Objetivo: presentar el escenario de producción de los Grupos de Investigación del Nordeste en Ciencias de la Información, registrados en el Diretório dos Grupos de Pesquisa no Brasil del Conselho Nacional de Desenvolvimento Científico e Tecnológico, sus principales enfoques temáticos y los vehículos de comunicación utilizados. Metodología: aplica el estudio de caso como método, utilizando el Diretório dos Grupos de Pesquisa y las producciones publicadas por los líderes del grupo en la base de datos de Web of Science como el instrumento de recolección de datos y la metodología de Análisis de Contenido para el análisis. Resultados: señala que los Grupos de Investigación en Ciencias de la Información del Nordeste se centran en la investigación relacionada con los temas: gestión, mediación y tecnología de la información, utilizando artículos en revistas científicas para difundir su investigación. Conclusiones: los grupos de investigación del noreste tienen publicaciones científicas de calidad y publicadas en revistas con Qualis/Capes, lo que demuestra el compromiso de los investigadores para producir conocimiento para el (re)uso por parte de la comunidad académica y, en consecuencia, para la sociedad.

Descriptores: Ciencia de la información. Comunicación científica. Gestión de la Información. Grupos de investigación. Producción científica.

Recebido em: 29.01.2020

Aceito em: 10.06.2020 